\title{
PERFIL FERMENTATIVO DA SILAGEM DE CAPIM-ELEFANTE ADICIONADA DE TORTA DE NABO FORRAGEIRO, PINHÃO MANSO OU TREMOÇO, EM DIFERENTES PROPORÇÕES
}

Arnaldo Prata Neiva Júnior ${ }^{1}$, José Cleto da Silva Filho² ${ }^{2}$ Edílson Rezende Cappelle ${ }^{1}$, Valdir Botega Tavares ${ }^{1}$, Paulo Ricardo Pereira Paula ${ }^{3}$, William Luiz de Souza ${ }^{4}$

\begin{abstract}
RESUMO - Objetivou-se avaliar a qualidade fermentativa da silagem de capim-elefante (Pennisetum purpureum) adicionada de tortas de nabo forrageiro (Raphanus sativus), de pinhão manso (Jatropha curcas) e de tremoço (Lupinus albus L). O experimento foi conduzido no Laboratório de Pesquisa Animal da Universidade Federal de Lavras (UFLA), onde os coprodutos foram ensilados em silos experimentais de PVC, adaptados com válvula tipo Bunsen. O delineamento utilizado foi o inteiramente casualizado (DIC) com três repetições, onde os tratamentos foram arranjados segundo um esquema de parcelas subdivididas no tempo. Foi utilizado o esquema fatorial $3 \times 3+1$, sendo 3 tipos de torta - nabo forrageiro (TNF), pinhão manso (TPM) e tremoço (TT); 3 níveis de inclusão de torta - 5, 8, e 11\% mais 1 tratamento adicional de capim-elefante. Foram determinados os valores de $\mathrm{pH}, \mathrm{N}-\mathrm{NH}_{3}$, poder tampão (PT) e ácido graxos voláteis (AGV's). Os valores de $\mathrm{pH}$ obtidos nas silagens experimentais, com exceção das contendo TPM nos níveis 5 e 11\%, e TT no nível $8 \%$ apresentaram valores considerados adequados. Houve efeito $(\mathrm{P}<0,05)$ do nível de adição das três tortas (TNF, TPM e TT) nas silagens de capim elefante, sendo que o menor valor foi observado no nível de inclusão 5\%, para TNF e TT. Já para TPM o menor valor de $\mathrm{N}_{-} \mathrm{NH}_{3}$ foi no nível $8 \%$. Os valores médios de PT indicam que a média do tratamento adicional é superior $(\mathrm{P}<0,05)$ à média da combinação dos fatores níveis e tortas. As silagens contendo TPM, com exceção dos valores de ácido propiônico, não apresentaram valores satisfatórios para serem classificadas como boas silagens, já que os valores de ácido acético foram superiores a $2 \%$ e os de ácido lático não entraram no intervalo de 4 a 6\%. As tortas proporcionam perfis fermentativos diferentes para as silagens, indicando redução no PT, sendo que a TNF e TT proporcionaram melhores níveis de ácido lático.
\end{abstract}

Palavras chave: co-produto, conservação, perfil fermentativo.

\section{FERMENTATION PROFILE OF ELEPHANT GRASS SILAGE ADDED WITH FORAGE TURNIP, JATROPHA OR LUPINE CAKE, IN DIFFERENT PROPORTIONS}

\begin{abstract}
The objective of this study was to evaluate the fermentative quality of elephant grass silage (Pennisetum purpureum) added with forage turnip (Raphanus sativus), jatropha curcas and lupine (Lupinus albus L). The experiment was conducted at the Laboratório de Pesquisa Animal da Universidade Federal de Lavras (UFLA), where the co-products were ensiled in experimental PVC silos, adapted with a Bunsentype valve. The design used was completely randomized with three replications, where the treatments were arranged according to a scheme of plots subdivided over time. The $3 \times 3+1$ factorial scheme was used, with 3 types of pie - forage turnip (FT), jatropha (PN) and lupine cake (L); 3 levels of pie inclusion - 5, 8, and
\end{abstract}

\footnotetext{
${ }^{1}$ Docentes, Departamento de Zootecnia, Instituto Federal de Educação, Ciência e Tecnologia do Sudeste de Minas Gerais. Rio Pomba, MG, Brasil. E-mail: arnaldo.junior@ifsudestemg.edu.br; cappelle@ifsudestemg.edu.br; valdir.botega@ifsudestemg.edu.br.

${ }^{2}$ Docente, Departamento de Zootecnia, Universidade Federal de Lavras. Lavras, MG, Brasil. E-mail: cleto@dzo.ufla.br.

${ }^{3}$ Zootecnista. E-mail: paulopereirazoo93@gmail.com.

${ }^{4}$ Discente, Curso de Mestrado, Programa de Pós-Graduação em Zootecnia, Universidade Estadual Paulista, UNESP, Jaboticabal, SP, Brasil. E-mail: williamluizdesouzaa@gmail.com.
} 
$11 \%$ plus 1 additional elephant grass treatment. The $\mathrm{pH}, \mathrm{N}-\mathrm{NH}_{3}$, buffering power (BP) and volatile fatty acid (VFA) values were determined. The $\mathrm{pH}$ values obtained in the experimental silages, with the exception of those containing PN at levels 5 and $11 \%$, and TT at level $8 \%$, presented values considered adequate. There was an effect $(P<0.05)$ of the level of addition of the three pies (FT, PN and L) on elephant grass silages, with the lowest value being observed at the inclusion level 5\%, for FT and L. For PN, the lowest value of $\mathrm{N}_{-} \mathrm{NH}_{3}$ was $8 \%$. The mean BP values indicate that the average of the additional treatment is higher $(P<0.05)$ than the average of the combination of the levels and tarts factors. The silages containing PN, with the exception of the propionic acid values, did not present satisfactory values to be classified as good silages, since the acetic acid values were higher than $2 \%$ and those of lactic acid did not fall in the range of 4 to $6 \%$. The pies provide differentiated fermentative characteristics for the silages, at the levels studied, indicating that they should be used differently, with FT and L providing silages with a better fermentation pattern.

Keywords: co-product, conservation, fermentative profile.

\section{INTRODUÇÃO}

A destinação imprópria de co-produtos da agroindústria, produzidos em larga escala em quase todo o Brasil hoje, é um problema que merece bastante atenção no que diz respeito à poluição ambiental. Dentre esses, destacam-se os co-produtos da indústria do biodiesel, como as tortas de nabo forrageiro, pinhão manso e tremoço.

Dentre as possibilidades de utilização desses coprodutos agroindustriais está o fornecimento como fonte de nutrientes em dietas para animais, que vem sendo praticado há décadas por nações industrializadas, onde milhões de toneladas desse material são produzidas a cada ano (Geron et al., 2018). Esse fato deve-se aos resultados de intensivas pesquisas desenvolvidas para encontrar métodos eficientes de reciclagem das "sobras" das indústrias.

Uma das características das forrageiras de clima tropical é o decréscimo do valor nutritivo com o avançar da idade da própria planta e uma das técnicas adotadas para manejo dessas forrageiras é a ensilagem deste material para melhor conservação do seu valor nutritivo. Dentre as gramíneas tropicais utilizadas para realização desta técnica de conservação de forragem está o capim-elefante (Pennisetum purpureum, Schum), que se caracteriza por apresentar alto potencial de produção e boa composição bromatológica (Tosi, 1973; Barcelos et al., 2018; Trindade et al., 2018). Porém, mesmo ao atingir um valor nutricional elevado, apresenta um baixo teor de carboidratos solúveis, em torno de $9 \%$ da matéria seca (MS), teores de MS em torno de $20 \%$ e alto poder tampão, fatores estes que podem influenciar negativamente o processo fermentativo (Evangelista et al., 2004). Algumas alternativas são utilizadas para elevar o teor de matéria seca e de carboidratos solúveis no material ensilado, aumentando consequentemente os padrões fermentativos da silagem. Sendo que, o aumento da matéria seca pode ser alcançado através de técnicas de emurchecimento do capim ou adição de aditivos, com intuito de buscar uma silagem de qualidade (Tosi et al., 1995, 1999; Carvalho et al., 2006; Bonfá et al., 2017; Maia et al., 2015; Tonin et al., 2018).

O processo de fermentação é muito complexo, envolvendo variações químicas e microbiológicas na massa ensilada, podendo resultar em uma silagem de boa ou de má qualidade. Para que se possa intervir no processo, fornecendo condições para uma boa fermentação, é preciso que se conheça o perfil de fermentação para cada planta utilizada.

O interesse em utilizar co-produtos agroindustriais do biodiesel na alimentação animal vem aumentando, porém ainda são escassos os trabalhos com dados sobre a sua utilização como aditivos sequestrante de umidade na ensilagem de capim-elefante. A utilização de aditivos sequestrantes de umidade tem por finalidade elevar os teores de matéria seca, juntamente com os teores de carboidratos solúveis que favorecendo a dinâmica de fermentação, consequentemente a conservação dos nutrientes da silagem (Santos et al., 2010; Yitbarek \& Tamir, 2014).

O objetivo deste trabalho foi avaliar o perfil fermentativo da silagem de capim-elefante (Pennisetum purpureum) adicionada de tortas de nabo forrageiro (Raphanus sativus), de pinhão manso (Jatropha curcas) e de tremoço (Lupinus albus L).

\section{MATERIAL E MÉTODOS}

O trabalho foi conduzido nas dependências do Departamento de Zootecnia da Universidade Federal de Lavras (UFLA), situada no município de Lavras, sul de Minas Gerais, posicionada a $21^{\circ} 14^{\prime}$ de latitude sul e $45^{\circ}$ 00 ' de longitude oeste de Greenwich, com altitude média 
de $918 \mathrm{~m}$. O clima, segundo a classificação de Koppen, é do tipo Cwa, tendo duas estações distintas: chuvosa (outubro a março), e seca (abril a setembro). A precipitação média anual é de $1529,7 \mathrm{~mm}$ e as temperaturas médias de máximas e mínimas são 26,1 e $14,8^{\circ} \mathrm{C}$, respectivamente, com temperatura média anual de $19,4^{\circ} \mathrm{C}$.

$\mathrm{O}$ experimento foi instalado segundo um delineamento inteiramente casualizado (DIC) com três repetições, em que os tratamentos estavam arranjados segundo um esquema fatorial 3 × 3 ( 3 tipos de torta - nabo, pinhão e tremoço; 3 níveis de inclusão de torta - 5, 8, e 11\%) mais 1 tratamento adicional, totalizando dez tratamentos como descrito a seguir (Tabela 1).

Tabela 1 - Tratamentos experimentais

\begin{tabular}{l}
$\mathrm{T} 1=$ ADICIONAL $=100 \%$ Capim elefante \\
$\mathrm{T} 2=95 \%$ Capim elefante $+5 \%$ Torta de nabo forrageiro \\
$\mathrm{T} 3=92 \%$ Capim elefante $+8 \%$ Torta de nabo forrageiro \\
$\mathrm{T} 4=89 \%$ Capim elefante $+11 \%$ Torta de nabo forrageiro \\
$\mathrm{T} 5=95 \%$ Capim elefante $+5 \%$ Torta de pinhão manso \\
$\mathrm{T} 6=92 \%$ Capim elefante $+8 \%$ Torta de pinhão manso \\
$\mathrm{T} 7=89 \%$ Capim elefante $+11 \%$ Torta de pinhão manso \\
$\mathrm{T} 8=95 \%$ Capim elefante $+5 \%$ Torta de tremoço \\
$\mathrm{T} 9=92 \%$ Capim elefante $+8 \%$ Torta de tremoço \\
$\mathrm{T} 10=89 \%$ Capim elefante $+11 \%$ Torta de tremoço \\
\hline
\end{tabular}

$\mathrm{Na}$ confecção das silagens foram utilizadas tortas de nabo forrageiro e de pinhão manso resultantes da extração "a frio" de óleo e de tremoço resultante da extração com solvente, para a produção de biodiesel. A extração foi feita com a utilização de uma miniprensa mecânica, de aço inoxidável, modelo MPE-40 da Ecirtec LTDA., com capacidade para extração de $40 \mathrm{~kg} / \mathrm{h}$.

As tortas foram obtidas no Departamento de Engenharia da Universidade Federal de Lavras - MG e o capim-elefante obtido no Departamento de Zootecnia do Instituo Federal de Educação, Ciência e Tecnologia do Sudeste de Minas Gerais - Campus Rio Pomba.

O capim-elefante foi picado em picadeira eletromecânica, antes de ser ensilado. Já as tortas (de nabo forrageiro, de pinhão manso e de tremoço) não sofreram nenhum tipo de pré-processamento.

As tortas foram pesadas e misturadas manualmente ao capim-elefante e o material foi ensilado em silos de PVC, com diâmetro de $10 \mathrm{~cm}$ e altura de $60 \mathrm{~cm}$, adaptados com válvula tipo Bunsen e com capacidade aproximada de quatro quilos de silagem.

A compactação da massa ensilada foi realizada manualmente com barra de ferro e madeira e, após a total compactação, os silos foram fechados, vedados com fita adesiva, identificados com etiquetas e acondicionados em local sob proteção da luz solar e chuva.

Foram retiradas amostras de cada resíduo isoladamente, bem como de cada tratamento antes da ensilagem, sendo que parte foi conservada em congelador e outra foi para a estufa de ventilação forçada a $65^{\circ} \mathrm{C}$ por 72 horas, moída e armazenada em potes de plástico (devidamente identificados) para análises posteriores.

O material permaneceu ensilado por 62 dias. Após esse período, os silos foram abertos e três amostras de cada um foram retiradas, tomando-se o cuidado em desprezar as partes superiores e inferiores do material ensilado. Dessas amostras, uma foi pesada e seca em estufa de ventilação forçada a $65^{\circ} \mathrm{C}$ por 72 horas e as outras foram colocadas em sacos plásticos devidamente identificados e guardadas em congelador. Uma amostra adicional de $250 \mathrm{~g}$ de cada tratamento foi tomada para a extração do suco da silagem para a determinação do $\mathrm{pH}$, nitrogênio amoniacal e ácidos graxos voláteis.

As análises laboratoriais foram realizadas no Laboratório de Pesquisa Animal do Departamento de Zootecnia da Universidade Federal de Lavras, MG. As amostras secas foram moídas em moinho do tipo Willey, com peneira de 30 mesh, armazenadas em potes plásticos devidamente identificados e encaminhadas ao laboratório. O teor de nitrogênio amoniacal no suco da silagem foi obtido de acordo com Bolsen et al. (1992). As medidas do $\mathrm{pH}$ foram feitas com o uso de um potenciômetro (Silva \& Queiroz, 2002). As determinações do poder tampão foram realizadas utilizando-se amostras do material original, de acordo com a técnica descrita por Playne \& McDonald (1966).

A determinação de ácidos graxos voláteis foi realizada no laboratório de nutrição animal da Universidade Federal de Minas Gerais - UFMG, de acordo com técnica de cromatografia gasosa, com equipamento Shimadzu CG17 A.

O modelo estatístico que descreve os dados é descrito como se segue:

$$
y_{i j}=\mu+a_{i}+\varepsilon_{i j} \text {, em que: }
$$

$y_{i j}$ é o valor da variável dependente na j-ésima repetição que recebeu o i-ésimo tratamento, com $\mathrm{j}=1,2,3$; 
$\mu$ é uma constante inerente a cada observação;

$a_{i}$ é o efeito do i-ésimo tratamento, com $\mathrm{i}=1, \ldots, 10$;

$\varepsilon_{i j}$ é o erro experimental normalmente distribuído com média zero e variância $\sigma^{2}$;

Para $\mathrm{i}=1,2,3,4,5,6,7,8,9$.

$a_{i}=n_{i}+t_{m}+n t_{l m}$

$n_{i}$ é o efeito do 1-ésimo nível de inclusão de torta, com $1=1,2,3$;

$t_{m}$ é o efeito do m-ésimo tipo de torta, com $\mathrm{m}=1,2$;

$n t_{l m}$ é o efeito da interação do l-ésimo nível de inclusão de torta com o m-ésimo tipo de torta;

Para $\mathrm{i}=7$.

$a_{i}=g_{n}$, em que:

$g_{n}$ é o efeito do tratamento adicional, com $\mathrm{n}=1$

Os dados foram submetidos à análise de variância utilizando rotinas do software Statistical Analysis System (SAS, 1999). A média dos tratamentos em esquema fatorial foram comparadas à média do tratamento adicional por meio do teste $\mathrm{F}$ da análise de variância, com um nível nominal de significância de $5 \%$. O efeito de tipos de torta, quando significativo, foram comparadas pelo teste $\mathrm{t}$ de Student, com um nível nominal de significância de 5\% e o efeito de níveis de inclusão de torta, quando significativos, tiveram suas médias comparadas pelo teste de Scott-Knott com o mesmo nível de significância.

\section{RESULTADOS E DISCUSSÃO}

Os valores de $\mathrm{pH}$ obtidos nas silagens experimentais (Tabela 2), com exceção das contendo TPM nos níveis 5 e 11\% (4,60 e 4,59, respectivamente), e TT no nível $8 \%(4,24)$ apresentaram valores considerados adequados.

Segundo Woolford (1984), o pH ideal resultante de uma boa fermentação deve ser menor que 4,2; porém, mesmo as silagens de capim-elefante puro, com $\mathrm{pH}$ de 4,21 , mostraram bom aspecto de conservação. Pahlow et al. (2003) preconizou que o valor de $\mathrm{pH}$ ideal da silagem de capim-elefante esteja em torno de 3,5 a 4,2, indicando uma silagem de boa qualidade. Pedreira et al. (2001), ensilando Tifton 85 submetido ao emurchecimento e à adição de polpa cítrica, encontraram valores de $\mathrm{pH}$ acima da faixa recomendada, variando de 4,9 a 5,6. A respeito destes valores, os autores concluíram que as silagens exibiram baixa proteólise, provavelmente em função da redução da atividade clostrídica, resultando na preservação das proteínas. Uma boa silagem deve ter um $\mathrm{pH}$ na faixa de 3,8 a 4,2 (Ruiz, 1992; Lavezzo, 1994).

Os valores de $\mathrm{pH}$ encontrados neste experimento foram superiores quando se adicionou TNF ao capimelefante e inferiores para TPM aos encontrados por Van Cleef (2008), em estudo com as mesmas tortas. Molina et al. (2002), avaliando silagens com diferentes aditivos, encontraram variações no $\mathrm{pH}$ entre 3,22 e 4,19.

Segundo Rotz \& Muck (1994), um dos princípios básicos da ensilagem é a inibição do desenvolvimento dos microrganismos da silagem pelo abaixamento do $\mathrm{pH}$ ou exaustão dos substratos. $\mathrm{O}$ pH final não pode ser tomado isoladamente como um bom critério para avaliação das fermentações, pois a inibição de fermentações secundárias depende mais da velocidade de abaixamento do mesmo, da concentração iônica e da umidade do meio do que do $\mathrm{pH}$ final do produto Woolford (1984).

Os valores médios de $\mathrm{pH}$ encontrados nas silagens contendo TNF foram menores $(\mathrm{P}<0,05)$ que os encontrados nas contendo TPM e TT, para os três níveis estudados (Tabela 2).

Os valores médios do $\mathrm{pH}$ nas silagens foram afetados $(\mathrm{P}<0,05)$ pelos níveis de inclusão das tortas (Tabela 2). A adição de 5 e $11 \%$ da TPM ao capim-elefante proporcionou elevados valores médios de $\mathrm{pH}$ (4,60 e 4,59 respectivamente). O melhor valor médio encontrado para silagens com essa torta foi de 4,13, valor esse que indicaria uma boa fermentação (Woolford, 1984).

Tabela 2 - Valores médios de pH das silagens, em função das tortas e dos níveis de inclusão

\begin{tabular}{lrrrr}
\hline \multirow{2}{*}{ Níveis $^{2}$} & \multicolumn{3}{c}{ Tortas $^{1}$} & \multirow{2}{*}{$\begin{array}{c}\text { Erro } \\
\text { padrão }\end{array}$} \\
\cline { 2 - 4 } & Nabo & Pinhão & Tremoço & \\
\hline 5 & $4,13 \mathrm{Ca}$ & $4,60 \mathrm{Aa}$ & $4,20 \mathrm{Ba}$ & \\
8 & $3,99 \mathrm{Cc}$ & $4,13 \mathrm{Bb}$ & $4,24 \mathrm{Aa}$ & 0,02 \\
11 & $4,07 \mathrm{Bb}$ & $4,59 \mathrm{Aa}$ & $4,08 \mathrm{Bb}$ & \\
\hline Erro padrão & \multicolumn{4}{c}{0,02} \\
\hline
\end{tabular}

${ }^{1}$ Médias seguidas de mesma letra maiúscula na linha, não diferem entre si pelo teste de Scott-Knott com um nível nominal de significância de $5 \% ;{ }^{2}$ Médias seguidas de mesma letra minúscula na coluna, não diferem entre si pelo teste de Scott-Knott com um nível nominal de significância de 5\%.

A média dos valores de $\mathrm{N}-\mathrm{NH}_{3}$ encontrados no suco das silagens do tratamento adicional é estatisticamente inferior às médias da combinação dos fatores níveis e tortas 
(Tabela 3). Sendo assim, pode-se inferir que a adição das tortas aumentou significativamente os teores de $\mathrm{N}-\mathrm{NH}_{3}$ nas silagens experimentais.

Tabela 3 - Valores médios do nitrogênio amoniacal $\left(\mathrm{N}-\mathrm{NH}_{3}\right)$ das silagens, em função do tratamento adicional e da combinação entre os fatores níveis e tortas

\begin{tabular}{lcc}
\hline Variável & ${ }^{1}$ Capim & ${ }^{1}$ Níveis*tortas \\
\cline { 2 - 3 }${ }^{2} \mathrm{~N} \mathrm{NH}_{3}$ & $4,49 \mathrm{~B}$ & $6,58 \mathrm{~A}$ \\
\hline
\end{tabular}

${ }^{1}$ Médias seguidas de mesma letra maiúscula, na linha, para o contraste (Adicional vs Fatorial) não diferem entre si pelo teste $\mathrm{F}$ com um nível nominal de significância de $5 \%{ }^{2}$ ( $\%$ no $\mathrm{N}$ total).

Houve efeito $(\mathrm{P}<0,05)$ do nível de adição das três tortas (TNF, TPM e TT) nas silagens de capim-elefante, sendo que o menor valor foi observado no nível de inclusão $5 \%$, para TNF e TT. Já para TPM o menor valor de $\mathrm{N}_{-} \mathrm{NH}_{3}$ foi no nível $8 \%$ (Tabela 4 ).

Tabela 4 - Valores médios de nitrogênio amoniacal das silagens, em função das tortas e dos níveis de inclusão

\begin{tabular}{lcccc}
\hline \multirow{2}{*}{ Níveis $^{2}$} & \multicolumn{3}{c}{ Tortas $^{1}$} & \multirow{2}{*}{$\begin{array}{c}\text { Erro } \\
\text { padrão }\end{array}$} \\
\cline { 2 - 4 } & Nabo & Pinhão & Tremoço & \\
\hline 5 & $4,43 \mathrm{Bc}$ & $7,74 \mathrm{Aa}$ & $7,55 \mathrm{Ac}$ & \\
8 & $4,94 \mathrm{Bb}$ & $4,13 \mathrm{Cc}$ & $9,74 \mathrm{Aa}$ & 0,07 \\
11 & $5,49 \mathrm{Ca}$ & $6,36 \mathrm{Bb}$ & $8,83 \mathrm{Ab}$ & \\
\hline Erro padrão & \multicolumn{5}{c}{0,07} \\
\hline
\end{tabular}

${ }^{1}$ Médias seguidas de mesma letra maiúscula na linha, não diferem entre si pelo teste de Scott-Knott com um nível nominal de significância de 5\%; ${ }^{2}$ Médias seguidas de mesma letra minúscula na coluna, não diferem entre si pelo teste de Scott-Knott com um nível nominal de significância de 5\%.

No geral, as adições de TNF, TPM e TT à silagem de capim-elefante provocaram algumas variações no teor de $\mathrm{N}_{-} \mathrm{NH}_{3}$ (\% $\mathrm{N}$ total), no entanto, todas as silagens apresentaram baixos teores, sendo classificadas como de boa qualidade. Uma silagem bem preservada deve apresentar teores de $\mathrm{N}-\mathrm{NH}_{3}$ (\% $\mathrm{N}$ total) menores que 10\% (McDonald, 1981). Analisando os dados na tabela 4, verifica-se que todas as silagens estão dentro de uma faixa considerada desejável de $\mathrm{N}_{-} \mathrm{NH}_{3}(\% \mathrm{~N}$ total), podendose concluir que durante o processo fermentativo, houve a preservação das proteínas, ou seja, não houve degradação ao ponto de reduzir o valor nutritivo das silagens.
Segundo Van Soest (1994), um baixo teor de nitrogênio amoniacal na silagem, inferior a $10 \%$ do nitrogênio total, indica que o processo de fermentação não resultou em quebra excessiva de proteína em amônia, e os aminoácidos constituem a maior parte do nitrogênio nãoprotéico.

Peres (1997), ao avaliar o efeito da utilização da polpa cítrica como aditivo na ensilagem do capim napier, utilizou valores de $0,5,10$ e $15 \%$ da matéria original. Os valores de $\mathrm{N}-\mathrm{NH}_{3}(\% \mathrm{~N}$ total) relatados foram de $12,7,11,8,11,5$ e $10,9 \%$, respectivamente, sendo superiores ao recomendado por Van Soest (1994). Da mesma forma, Ferrari Júnior \& Lavezzo (2001), para a silagem de capim-elefante cv. Taiwan A-146, adicionada de farelo de mandioca nos níveis de $0 \%, 2 \%, 4 \%, 8 \%$ e $12 \%$, encontraram valores de $\mathrm{N}_{-} \mathrm{NH}_{3}(\% \mathrm{~N}$ total $)$ de 17,$52 ; 18,99 ; 17,76 ; 18,87$ e 18,97 , respectivamente, e portanto, superiores aos citados por Van Soest (1994). Araújo et al. (2000), estudando o perfil de fermentação de silagens de três cultivares de milheto, observaram que para as concentrações de $\mathrm{N}-\mathrm{NH}_{3}(\% \mathrm{~N}$ total) ocorreram variações entre $3,32 \%$ no primeiro dia, e $9,01 \%$, com 56 dias de fermentação, aumentando com o passar dos dias sem tendência à estabilização dos valores até os 56 dias de fermentação. Outros autores também não observaram tendência de estabilização dos valores de $\mathrm{N}_{-} \mathrm{NH}_{3}(\% \mathrm{~N}$ total) para as silagens de milho (Antunes et al., 2000) e de girassol (Pereira et al., 1999).

Furtado et al. (2019), avaliando o efeito da utilização de casca de mamona na ensilagem de capim elefante, com inclusão de 0, 10, 20 e 30\%. A silagem de capim elefante com $0 \%$ inclusão da casca de mamona mostrou um valor de $\mathrm{N}_{-} \mathrm{NH}_{3}$ acima de $12 \%$, valor relatado por McDonald, Henderson e Heron (1991) como característica de silagem de baixa qualidade com alta degradação de proteína bruta, indicando que esta requer algum aditivo para minimizar as perdas de nitrogênio compostos. No entanto, em silagens com proporções de 10,20 ou $30 \%$ de casca de mamona, esta variável apresentou valores inferiores a $10 \%$, indicando processo de fermentação adequado e baixa hidrólise de proteínas e compostos nitrogenados (Van Soest, 1994).

Os valores médios de PT (Tabela 5) indicam que a média do tratamento adicional é superior $(\mathrm{P}<0,05)$ à média da combinação dos fatores níveis e tortas. Sendo assim, pode-se inferir que a adição das tortas nos níveis utilizados, fez com que os valores de PT fossem diminuí$\operatorname{dos}(\mathrm{P}<0,05)$. 
Tabela 5 - Valores médios da variável de poder tampão (PT) das silagens, em função do tratamento adicional e da combinação dos níveis e tortas

\begin{tabular}{lll}
\hline Variável & ${ }^{1}$ Capim & ${ }^{1}$ Níveis*tortas \\
\cline { 2 - 3 } PT & $35,28 \mathrm{~A}$ & $28,12 \mathrm{~B}$ \\
\hline
\end{tabular}

${ }^{1}$ Médias seguidas de mesma letra maiúscula, na linha, para o contraste (Adicional vs Fatorial) não diferem entre si pelo teste F com um nível nominal de significância de 5\%.

Não houve diferença $(\mathrm{P}>0,05)$ entre os valores médios de PT do material contendo as TNF e TPM nos níveis $5 \%$ e $8 \%$ (Tabela 6 ). Já no nível $11 \%$ houve diferença $(\mathrm{P}<0,05)$, sendo que os menores valores médios foram observados nos que continham TNF, seguido da TPM e TT.

Chiou (2000) encontrou valores de poder tampão de 38,$0 ; 35,3 ; 25,4$ e 20,5 Emg de $\mathrm{NaOH} / 100$ g de MS para o capim-elefante cultivar Napier com a inclusão de 60, 40, 20 e $0 \%$ de grãos de sorgo, respectivamente.

Os ácidos orgânicos e seus sais são os constituintes tamponantes mais importantes das plantas. A fração aniônica de culturas forrageiras, representada pelos ácidos orgânicos, sulfatos, nitratos e cloretos, representa 60 a $80 \%$ dos constituintes tamponantes na silagem, enquanto as proteínas vegetais representam somente 10 a 20\% (Dune, 1982, citado por Woolford, 1984).

Não houve efeito $(\mathrm{P}>0,05)$ de níveis sobre o PT do material contendo TPM e TT. Já o que continha TNF houve diferença $(\mathrm{P}<0,05)$ entre os níveis de inclusão, sendo que o menor valor de PT foi observado no nível 11\% (Tabela 6).

Tabela 6 - Valores médios de poder tampão das silagens, em função das tortas e dos -níveis de inclusão

\begin{tabular}{lcccc}
\hline \multirow{2}{*}{ Níveis $^{2}$} & \multicolumn{3}{c}{ Tortas $^{1}$} & $\begin{array}{c}\text { Erro } \\
\text { padrão }\end{array}$ \\
\cline { 2 - 4 } 5 & Nabo & Pinhão & Tremoço & para \\
8 & $30,83 \mathrm{Aa}$ & $31,10 \mathrm{Aa}$ & $31,82 \mathrm{Aa}$ & \\
11 & $26,13 \mathrm{Ab}$ & $28,15 \mathrm{Ab}$ & $29,60 \mathrm{Aa}$ & 0,91 \\
\hline Erro padrão & $19,18 \mathrm{Bc}$ & $27,55 \mathrm{Ab}$ & $28,68 \mathrm{Aa}$ & \\
\hline
\end{tabular}

${ }^{1}$ Médias seguidas de mesma letra maiúscula na linha, não diferem entre si pelo teste de Scott-Knott com um nível nominal de significância de $5 \% ;{ }^{2}$ Médias seguidas de mesma letra minúscula na coluna, não diferem entre si pelo teste de Scott-Knott com um nível nominal de significância de 5\%.

Os resultados obtidos na análise de AGV das silagens de capim elefante e nas silagens de capim com os co-produtos, encontram-se na Tabela 7.

Tabela 7 - Médias dos valores de ácidos graxos voláteis das silagens experimentais

\begin{tabular}{|c|c|c|c|c|c|}
\hline \multirow{2}{*}{ Silagens } & \multirow{2}{*}{$\begin{array}{l}\text { Nível de } \\
\text { inclusão dos } \\
\text { co-produtos } \\
(\%)\end{array}$} & \multicolumn{4}{|c|}{ Ácidos Graxos Voláteis/100g MS } \\
\hline & & Acético & Propiônico & Butirico & Lático \\
\hline $\mathrm{CE}^{1}$ & 0 & 1,59 & 0,05 & 0,03 & 2,65 \\
\hline $\mathrm{CE}+\mathrm{TNF}^{2}$ & 5 & 1,26 & $*$ & 0,03 & 4,82 \\
\hline $\mathrm{CE}+\mathrm{TNF}$ & 8 & 1,37 & * & 0,04 & 6,67 \\
\hline $\mathrm{CE}+\mathrm{TNF}$ & 11 & 1,43 & * & 0,04 & 6,71 \\
\hline $\mathrm{CE}+\mathrm{TPM}^{3}$ & 5 & 2,30 & 0,22 & 0,03 & 2,95 \\
\hline $\mathrm{CE}+\mathrm{TPM}$ & 8 & 2,19 & 0,23 & 0,20 & 2,89 \\
\hline $\mathrm{CE}+\mathrm{TPM}$ & 11 & 2,35 & 0,33 & 0,60 & 1,58 \\
\hline $\mathrm{CE}+\mathrm{TT}^{4}$ & 5 & 1,32 & * & $*$ & 4,77 \\
\hline $\mathrm{CE}+\mathrm{TT}$ & 8 & 1,34 & * & 0,03 & 6,58 \\
\hline $\mathrm{CE}+\mathrm{TT}$ & 11 & 1,44 & $*$ & 0,02 & 6,69 \\
\hline
\end{tabular}

${ }^{1}$ Silagem de capim elefante; ${ }^{2}$ Silagem de capim elefante com torta de nabo forrageiro; ${ }^{3}$ Silagem de capim elefante com torta de pinhão manso; ${ }^{4}$ Silagem de capim elefante com torta de tremoço; $*$ valores menores que $0,01 \%$. 
Analisando os dados de AGV obtidos neste experimento (Tabela 7), pode-se observar que os ácidos acético, propiônico e butírico nas silagens com TPM apresentaram um valor maior que os apresentados na silagem de somente capim-elefante e nas silagens contendo TNF ou TT. Isso se deve à menor concentração de carboidratos de fermentação rápida na torta do pinhão manso.

De acordo com Silveira (1975), todos os ácidos orgânicos que aparecem na silagem contribuem para a acidez total da mesma. Entretanto, o ácido lático é o maior responsável pelo abaixamento do $\mathrm{pH}$ pela sua maior constante de dissociação. Os valores para o ácido lático foram maiores nas silagens com TNF do que nas silagens de CE e de CE contendo TPM ou TT.

Os valores dos ácidos acético para a silagem de capim, e silagens com TNF e TT (Tabela 7) foram satisfatórios para que houvesse bom padrão de fermentação, que segundo Roth \& Undersander (1995), são de, no máximo, $2 \%$ de ácido acético, $0,5 \%$ de ácido propiônico, $0,1 \%$ de ácido butírico.

Considerando o valor de ácido lático, a única silagem que se pode ser classificada como ruim $(<2,0)$, de acordo com Rodriguez et al. (1999) é a contendo 11\% de TPM. Já as outras podem ser classificadas de satisfatórias $(3,0-2,0)$, boas $(5,0-$ $3,0)$ e muito boas $(>5,0)$, sendo que as melhores classificadas foram as contendo $11 \%$ de TNF e $11 \% \mathrm{TT}$.

As silagens contendo TPM, com exceção dos valores de ácido propiônico (que foram menores que $0,5 \%$ ), não apresentaram valores satisfatórios para serem classificadas como boas silagens (Tabela 7), já que os valores de ácido acético foram superiores a $2 \%$ e os de ácido lático não entraram no intervalo de 4 a $6 \%$. Resultados semelhantes foram encontrados por Van Cleef (2008).

\section{CONCLUSÃO}

As inclusões de tortas nas silagens proporcionaram perfis fermentativos diferentes, sendo promovido a redução do poder tampão quando comparado a silagem de capim-elefante sem inclusão de torta. Houve também elevação dos níveis de ácido lático em todos os níveis de inclusão de tortas de nabo forrageiro e tremoço.

\section{LITERATURA CITADA}

ANTUNES, R. C.; REIS, R. B.; GONÇALVES, L. C.; BORGES, I.; RODRIGUES, J. A. S.; RODRIGUEZ, N. M.; BORGES, A. L. C.; COSTA, R. S. Padrão de fermentação das silagens de seis genótipos de milho. In: REUNIÃO ANUAL DA SOCIEDADE BRASILEIRA DE ZOOTECNIA, 37., 2000, Viçosa-MG. Anais... Viçosa: SBZ, 2000. CD-ROM.

ARAÚJO, V. L.; RODRIGUEZ, N. M.; GONÇALVES, L. C.; BORGES, I.; RODRIGUES, J. A. S.; BORGES, A. L. C.; ALMEIDA, P. M. A.; PEREIRA, L. G. R. Qualidade e perfil de fermentação das silagens de três cultivares de milheto. . In: REUNIÃO ANUAL DA SOCIEDADE BRASILEIRA DE ZOOTECNIA, 37., 2000, Viçosa-MG. Anais... Viçosa: SBZ, 2000. CD-ROM.

BARCELOS, A. F. et al. Valor nutritivo e características fermentativas da silagem de capim-elefante com diferentes proporções de casca de café. Ciência Animal Brasileira, v. 19, p. 1-12, 2018.

BOLSEN, K.K.; LIN, B.E.; BRENT, B.E. et al. Effect of silage additives on the microbial succession and fermentation process of alfalfa and corn silage. J. Dairy Sci., v.75, p.3066-3083, 1992.

Bonfá, C. S.; Villela, S. D. J.; Castro, G. H. D. F.; Santos, R. A. D.; Evangelista, A. R.; Neto, P.; de Souza, O. Silagem de capim-elefante adicionada de casca de abacaxi. Ceres, v. 64, n. 2, 2017.

CARVALHO, G.G.P. Capim-Elefante emurchecido ou com farelo de cacau na produção de silagem. Viçosa-MG, 69f. Dissertação de (Mestrado) Universidade Federal de Viçosa, 2006.

CHIOU, P. W.; CHANG, S.; YU, B. The effects of wet sorghum distillers grains inclusion on napiergrass silage quality. Journal of the Science of Food and Agriculture, London, v. 80, n. 8, p. 1199-1205, Aug. 2000.

EVANGELISTA, A. R.; ABREU, J. G. D.; AMARAL, P. N. C. D.; PEREIRA, R. C.; SALVADOR, F. M.; SANTANA, R. A. V. Produção de silagem de capimmarandu (Brachiaria brizantha stapf cv. Marandu) com e sem emurchecimento. Ciência e Agrotecnologia, v. 28, n. 2, p. 443-449, 2004.

FERRARI JÚNIOR, E.; LAVEZZO, W. Qualidade da silagem de capim-elefante (Pennisetum purpureum Schum.) emurchecido ou acrescido de farelo de mandioca. Revista Brasileira de Zootecnia, v. 30, n. 5, p. 1424-1431, set./out. 2001.

FURTADO, R. N,; CARNEIRO, M.S.S.; COUTINHO, D. N.; CÂNDIDO, M. J. D.; SILA, E. B.Perdas fermentativas e composição química de silagens de capim-elefante aditivadas com casca de mamona. Revista Ciência Agronômica, v. 50, n. 1, p. 140-147, jan-mar, 2019. 
GERON, L. J. V. et al. Viabilidade técnica e econômica do uso de diferentes níveis de grãos secos de destilaria com solúveis (Zea Mays L.) em borregas terminadas em confinamento. Boletim de Indústria Animal, v. 75, 2018.

LAVEZZO, W. Ensilagem do capim elefante. In: SIMPÓSIO SOBRE MANEJO DO CAPIM ELEFANTE, 10., 1994, Piracicaba. Anais... Piracicaba: FEALQ/ESALQ, 1994. p. 169-275.

MAIA, I. S. A. et al. Valor nutritivo de silagens de capim elefante com níveis crescentes de resíduo da agroindústria da acerola. Acta Veterinaria Brasilica, v. 9, n. 2, p. 190194, 2015.

McDONALD, P. The Biochemistry of silage. New York: John Wiley, 1981. 207 p.

McDONALD, P.; HENDERSON, A. R.; HERON, S. J. E. The biochemistry of silage. New York: Chalcombe, 1991. $339 \mathrm{p}$.

MOLINA, L. R.; FERREIRA, D. A.; GONÇALVES, L. C.; CASTRO NETO, A. G.; RODRIGUES, N. M. Padrão de fermentação da silagem de cana-de-açúcar (Saccharum officinarum L.) submetida a diferentes tratamentos. In: REUNIÃO ANUAL DA SOCIEDADE BRASILEIRA DE ZOOTECNIA, 39., 2002, Recife. Anais... Recife: SBZ, 2002. CD-ROM.

PAHLOW, G.; MUCK, R.E.; DRIEHUIS, F.; ELFERINK, S.J.W.H.O.; SPOELSTRA, S.F. Microbiology of ensiling. In: BUXTON, D.R.; MUCK, R.E.; HARRISON, J.H. Silage science and technology. Madison: American Society of Agronomy, 2003. p.31-94.

PEDREIRA, M.S. et al. Características químicas e fermentativas do Tifton 85 (Cynodon spp.) ensilado com diferentes conteúdo de matéria seca e níveis de polpa cítrica. In: REUNIÃO ANUAL DA SOCIEDADE BRASILEIRA DE ZOOTECNIA. 38., Piracicaba, 2001. Anais... Piracicaba: FEALQ, 2001. p. 100-102

PEREIRA, L. G. R.; GONÇALVES, L. C.; RODRIGUES, J. A. S.; TOMICH, T. R.; BORGES, I.; RODRIGUEZ, N. M. Padrão de fermentação das silagens de seis genótipos de girassol (Helianthus annus L.). In: REUNIÃO ANUAL DA SOCIEDADE BRASILEIRA DE ZOOTECNIA, 36., 1999, Porto Alegre-RS. Anais... Porto Alegre: SBZ, 1999. CD-ROM.

PERES, J. R. Avaliação da polpa de citros seca e peletizada como aditivo na ensilagem do capim elefante (Pennisetum purpureum, SCHUM). 1997, 82 p. Dissertação (Mestrado) - Escola Superior de Agricultura "Luiz de Queiroz", Piracicaba.
PLAYNE, M. J.; MCDONALD, P. The buffering constituents of herbage and of silage. Journal of the Science of Food and Agriculture, v. 17, n. 6, p. 264-268, 1966.

RODRIGUEZ, N. M.; GONÇALVES, L. C.; NOGUEIRA, F. A. S. et al. Silagem de sorgo de porte baixo com diferentes teores de tanino e de umidade no colma. I- $\mathrm{pH}$ e teores de matéria seca e de ácidos graxos durante a fermentação. Arquivo Brasileiro de Medicina Veterinária e Zootecnia, v. 51, p. 485-490, 1999.

ROTH, G.; UNDERSTANDER, D. Silage additives. In: CORN SILAGE PRODUCTION MANAGEMENT AND FEEDING. Madison: Madison American Society of Agronomy, 1995. p. 27-29.

ROTZ, C. A.; MUCK, R. E. Changes in forage quality during harvest and storage. In: Forage quality, evaluation and utilization. Madison: ASA/CSSA/SSSA, 1994. p. 828868 .

RUIZ, R. L. Microbiologia zootécnica. São Paulo: Roca, 1992. 314 p.

SANTOS, M. V. F.; GÓMEZ CASTRO, A. G.; PEREA, J. M.; GARCÍA, A.; GUIM, A.; PÉREZ HERNÁNDEZ, M. Fatores que afetam o valor nutritivo das silagens de forrageiras tropicais. Archivos de Zootecnia, v. 59, n.2, p. 25-43, 2010.

SAS Institute. SAS Procedures guide for computers. 6 ed. cary, NC, v.3, 1999. 373p.

SILVA, D. J; QUEIROZ, A. C. Análise de alimentos: métodos químicos e biológicos. Viçosa, MG: UFV, 2002. $235 \mathrm{p}$.

SILVA, G. M.; SILVA, F. F.; SCHIO, A. R.; MENESES, M. A.; BALISA, D. L.; SOUZA, D. D.; SOARES, M. S.; SILVA, L. G.; VIANA, P. T.; CAIRES, R. S. Fatores antiqualitativos em silagens. PUBVET, v. 9, p. 502-557, 2015.

SILVEIRA, A. C. Técnicas para produção de silagem. In: SIMPÓSIO SOBRE MANEJO DA PASTAGEM, 2., 1975, Piracicaba. Anais... Piracicaba: ESALq, 1975. p.156-180.

TONIN, T. J. et al. Substituição do milho moído pela glicerina como aditivo em silagem de capim elefante. Boletim de Indústria Animal, v. 75, 2018.

TOSI, H. Conservação de forragem como conseqüência do manejo. In: SIMPÓSIO SOBRE MANEJO DE PASTAGENS, 1., 1973, Piracicaba. Anais... Piracicaba: ESALQ, 1973. p.117-140.

TOSI, H.; RODRIGUES, L. R. A.; JOBIM, C. C.; OLIVEIRA, M. S.; SAMPAIO, A. A. M.; ROSA, B. Ensilagem do capim elefante cv. Mott sob diferentes 
tratamentos. Revista Brasileira de Zootecnia, Viçosa, v. 24, n. 6, p. 909-916, 1995.

TOSI, P.; MATTOS, W.R.S.; TOSI, H. Avaliação do capim elefante (Pennisetum purpurem Schum.) cultivar Taiwan A-148, ensilado com diferentes técnicas de redução de umidade. Revista Brasileira de Zootecnia, v.28, n.5, p.947954, 1999.

TRINDADE, P. C.; LANA, R. P.; VELOSO, C. M.; PEREIRA, D. S. Desempenho agronômico e qualidade da silagem do capim elefante com adubação orgânica. Revista Brasileira de Agropecuária Sustentável. v.8, n.2, p.62-70, 2018.

VAN CLEEF, E.H.C.B. Composição das tortas de nabo forrageiro (Raphanus sativus) e pinhão manso (Jatropha curcas) e qualidade de silagens de capim elefante (Pennisetum purpureum) contendo estes subprodutos. 2008. 77p. Dissertação (Mestrado em Zootecnia) - Universidade Federal de Lavras, Lavras, MG.

VAN SOEST, P. J. Nutritional ecology of the ruminant. 2.ed. Corvalis: O e B Books, 1994. 476 p.

WOOLFORD, M. K. The silage fermentation. New York: Marcel Dekker, 1984. 350 p.

YITBAREK, M.; TAMIR, B. Silage additives: review. Open Journal of Applied Sciences. v.4, n.4, p.258-274, 2014.

Recebido para publicação em 01/05/2019, aprovado em 11/05/2020 e publicado 30/07/2020. 